\title{
AVO forward modeling and attributes analysis for fluid's identification: a case study
}

\author{
Nisar Ahmed • Perveiz Khalid • Shahid Ghazi • \\ Abdul Waheed Anwar
}

Received: 2 September 2014 / Accepted: 19 December 2015 / Published online: 7 January 2015 (C) Akadémiai Kiadó 2015

\begin{abstract}
Since the four decades amplitude versus offset (AVO) analysis is used extensively in hydrocarbon exploration to discriminate the hydrocarbon fluids from background geology. Conventionally AVO analysis involves calculation of intercept and gradient from a linear fit of compressional wave reflection coefficient to the sine square of the angle of incidence. Mississauga formation of early cretaceous is the reservoir rock in the study area, contains hydrocarbons and condensates in the middle part. It is very difficult to discriminate hydrocarbon fluids from non pay zones due to small thickness and low quality of pay zone. AVO forward modeling is done to estimate and analyze various AVO derived attributes for the discrimination of hydrocarbon from background sand. After calculating the AVO attributes, appropriate pairs of these attributes are crossplotted so that the hydrocarbon and non-hydrocarbon facies cluster together for quick identification and interpretation. In intercept/gradient crossplot the top of the gas zone falls in quadrant II and show clear deviation from background trend. The analysis reveals that oil and gas sand attributes are strongly different from water sand attributes. Among various attributes, the fluid factor and intercept are more promising attribute for fluid discrimination.
\end{abstract}

Keywords AVO attributes · AVO forward modeling · Pore fluids · Rock physics · Fluid substitution $\cdot$ Reflection coefficients

\section{Introduction}

Amplitude versus offset (AVO) analysis has been widely used in hydrocarbon exploration to discriminate hydrocarbon and non-hydrocarbon hosting rocks (Jing-Ye 2012; Hilterman

N. Ahmed $\cdot$ P. Khalid $(\bowtie) \cdot$ S. Ghazi

Institute of Geology, University of the Punjab, Lahore 54590, Pakistan

e-mail: perveiz.geo@pu.edu.pk

A. W. Anwar

Department of Physics, University of Engineering and Technology, Lahore, Pakistan 
2001). Amplitude versus angle based anomalies can be modified significantly by natural variations in fluids (oil, gas or brine) properties (Batzle et al. 2001; Khalid and Ghazi 2013). AVO analysis for the discrimination of hydrocarbon fluids from background geology (non pay zone) is facilitated by the crossplotting of extracted attributes and therefore, it can be used as a diagnostic tool for classifying the AVO response (Castagna and Swan 1997; Foster et al. 1997; Castagna et al. 1998; Ross 2000; Chopra et al. 2003) and for identifying hydrocarbon facies (Ross and Kinman 1995; Verm and Hilterman 1995). Intercept and gradient are the primary attributes that can be extracted from common depth point (CDP) gathers or these can be computed through mathematical equations (Castagna and Smith 1994; Ahmed 2013). The conventional amplitude anomalies are the function of compressional wave velocity $\left(V_{P}\right)$, shear wave velocity $\left(V_{S}\right)$, effective density $\left(\rho_{\text {eff }}\right)$ and the incident angle of seismic waves. The first three parameters are complex function of various rock-fluid properties (Mavko et al. 2009; Khalid et al. 2014a).

Zoeppritz equations are widely used for AVO analysis and to model energy partitioning on a geological interface. However, these equations are very complex; therefore many other geoscientists (Bortfeld 1961; Aki and Richards 1980; Shuey 1985; Smith and Gidlow 1987; Fatti et al. 1994; Verm and Hilterman 1995; Gray et al. 1999) gave linearized approximations of these. These linearized equations give more intuitive AVO attributes that help to discriminate the fluids and lithologies. Shuey (1985) proposed intercept-gradient methods, fluid factor (Smith and Gidlow 1987), impedances (Fatti et al. 1994), Poisson reflectivity (Verm and Hilterman 1995), elastic impedance (Connolly 1999), Poisson impedance (Quakenbush et al. 2006), elastic parameters (Goodway et al. 1997; Chen et al. 1998; Berryman et al. 2002; Gray et al. 1999; Khalid et al. 2014b), the pore space modulus (Hedlin 2000) and generalized fluid method (Russell et al. 2003). A large number of AVO derived attributes are in practice to discriminate hydrocarbon and non-hydrocarbon saturated reservoir rocks (Swan 1993; Castagna and Smith 1994; Thaper 2012).

In the present study, we have analyzed how the AVO forward modeling and various attributes help to identify the hydrocarbon containing sand facies from non-reservoir facies and fluid discrimination of the Early Cretaceous Mississauga Formation in Penobscot area of Nova Scotia. The extraction of AVO attributes help us to analyze that how the behavior of hydrocarbon bearing sand changes with pore fluid. After computing the various AVO attributes, we have crossplotted the appropriate pairs of these attribute to discriminate pore fluids. Gassmann's equation (1951) is used to quantify the fluid's effect on seismic parameters and on AVO attributes at in situ conditions.

\section{Methodology for AVO attributes analyses}

After the collection of data set used in the present study we check its quality. The 3D seismic data along with wireline logs of L-30 well in the Penobscot area, Nova Scotia is used for AVO forward modeling and to extract the pre-stack AVO attributes. The wireline logs include the gamma ray (GR), caliper, spontaneous potential (SP), density (RHOB), resistivity, neutron porosity and sonic (DT). In the next, we have explained the methodology adopted for this research and formulation and algorithms of all steps in more detail.

In the very first step we have mapped the reservoir by using 3D seismic and prepared the time structure map and then we have analyzed the available wireline logs for petrophysical parameters evaluation and to mark different lithologies, facies changes in the different units and hydrocarbon containing zone in the Mississauga Formation. The parameters like shale volume, porosity, seismic velocities, density, temperature and pressure from petrophysical 
studies are used in the rock physics modeling to derive seismic parameters at desired fluid saturations.

After mapping the reservoir seismically and petrophysical analysis we proceed for AVO forward modeling and attribute extraction. The methodology for forward modeling and attributes extraction is very simple and straightforward. The understanding of, how seismic properties $\left(V_{P}, V_{S}, \rho_{\text {eff }}\right)$ are effected by pore fluid type and mineralogy is a fundamental for successful prediction of reservoir characteristics. Moreover, the selection of appropriate AVO attribute is also depends on the reservoir type and fluid saturation. Since the reflected P-wave amplitude $\left(R_{P}\right)$ at an interface is a function $V_{P}, V_{S}$ and $\rho_{\text {eff }}$ of upper and lower mediums, therefore shear wave log, sonic log and density log are important for AVO forward modeling and pre-stack attribute computations. In case of non-availability of shear log, it can be computed using a number of lithology-based regression algorithms (Castagna et al. 1985; Krief et al. 1990; Greenberg and Castagna 1992). In the present study we have used Castagna's equation (1985) given below:

$$
V_{P}=1.16 V_{S}+1.36
$$

Here the velocity is in $\mathrm{km} / \mathrm{s}$.

Fluid substitution analysis in the reservoir rock is common practice in AVO modeling (Ross 2000; Russell et al. 2003), which make easy to distinguish fluid nature and its quantity in reservoirs. Fluid substitution provides the understanding and interprets how seismic parameters depend on pore fluid (water, oil or gas) saturation. Gassmann's equation (1951) is at the core of the matter, which predicts how pore fluids affect the rock moduli without referring pore shape and is more frequently used in fluid substitution modeling. It provides a relation to compute the bulk modulus of a fluid saturated porous rock $\left(K_{\text {sat }}\right)$ using the known bulk moduli of solid matrix (consist of rock forming minerals, $K_{m a t}$ ), of the frame (dry rock or rock sample with empty pore, $\left.K_{d r y}\right)$ and of the pore fluid $\left(K_{f l}\right)$. The Gassmann's equation for bulk modulus of saturated rock in its simplest form is give as

$$
K_{\text {sat }}=K_{d r y}+\beta^{2} M
$$

where $\beta$ is the Biot's coefficient (Biot 1941) or coefficient of effective stress and $M$ is the $\mathrm{P}$-wave modulus defined as

$$
\beta=1-K_{d r y} / K_{m a t}
$$

and

$$
M=\frac{\phi}{K_{f l}}+\frac{\beta-\phi}{K_{m a t}}
$$

The dry rock modulus is estimated as function of porosity by using Murphy et al. (1993) proposed empirical relation, bulk modulus of rock forming minerals is computed using VoigtReuss-Hill (VRH) average methods (Voigt 1910; Reuss 1929; Hill 1952) and the modulus of the mixture of fluid can be computed using Wood's equation (Wood 1941). Finally P and $\mathrm{S}$ wave velocities are find out by using the relations

$$
\begin{aligned}
& V_{P}=\left(\frac{K_{\text {sat }}+4 \mu / 3}{\rho_{\text {eff }}}\right)^{1 / 2} \\
& V_{S}=\left(\frac{\mu}{\rho_{\text {eff }}}\right)^{1 / 2}
\end{aligned}
$$




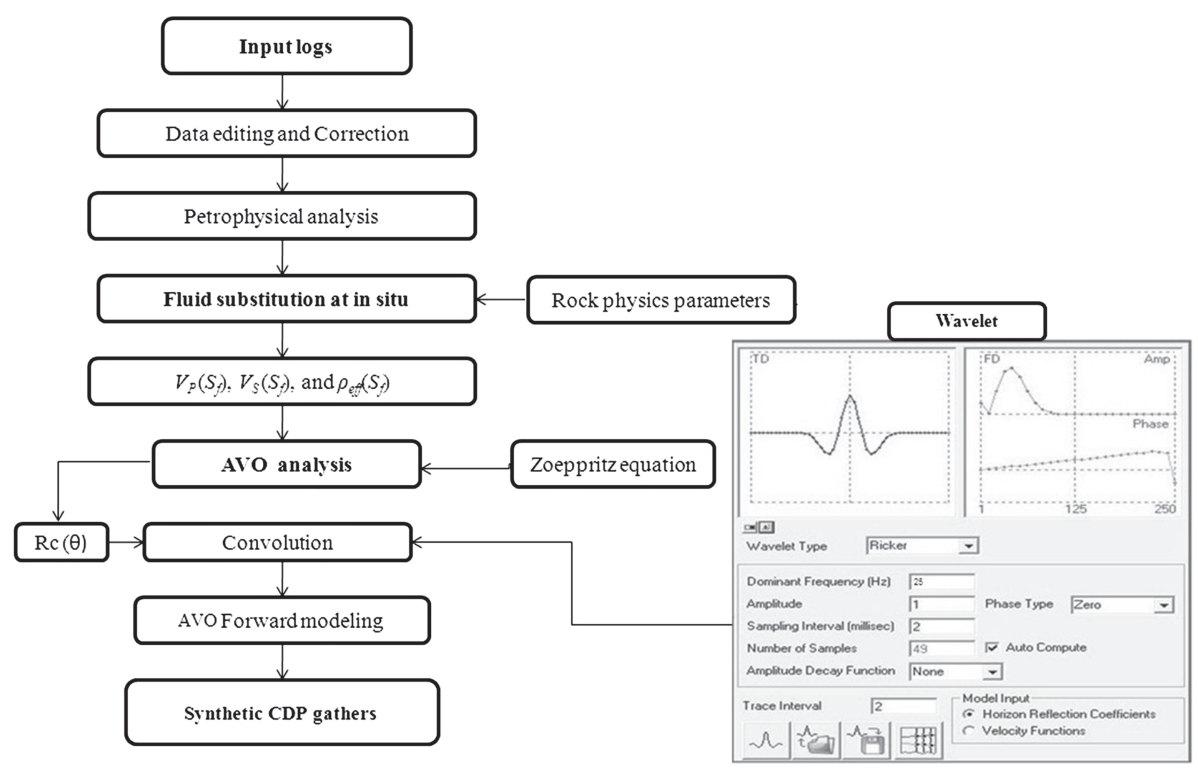

Fig. 1 A complete work flow adopted for AVO forward modeling at in situ

where

$$
\rho_{e f f}=(1-\phi) \rho_{m a t}+\phi \rho_{f l}
$$

whereas $\rho_{\text {mat }}$ and $\rho_{f l}$ are the matrix and fluid densities respectively. The seismic parameters $\left(V_{P}, V_{S}, \rho_{e f f}\right)$ as a function of pore fluids computed via fluid substitution modeling further are used in forward modeling to derive AVO attributes.

For AVO forward modeling (synthetic seismogram generation), we have used the exact Zoeppritz equations (1919) to calculate the reflection coefficients as a function of incident angles. These reflection coefficients are convolved with zero phase Ricker wavelet to generate the synthetic CDP gathers at different fluid saturations. Since our reservoir lies at the depth of $2638 \mathrm{~m}$ that's why for synthetic forward modeling we have used a wavelet of dominant frequency $25 \mathrm{~Hz}$. We have transferred the $R_{P P}$ from the Zoeppritz equations to K-tron $\mathrm{X}$-works seismic modeling engine using OIL script (Khan et al. 2010) and produce CDP gathers. Figure 1 represents the complete work flow adopted for synthetic forward modeling at reservoir interface. The seismic velocities and effective densities at reservoir conditions at different fluid saturations are calculated using Gassmann's relation (1951) as explained above. The seismic parameters of the seal rock (upper shale) and in the pay sand 4 intervals for different pore fluids and saturations are used to model the AVO response and to generate CDP gathers. The seismic parameters in upper shale and in the reservoir interval for different pore fluids (oil, gas, brine) are given in the Table 1. By using these parameters into Zoeppritz equation, the $\mathrm{P}$ wave reflection coefficients $\left(R_{P P}\right)$ as a function of incident angles $(\theta)$ at shale/pay sand 4 interfaces are computed.

Now we have described the complete set of mathematical equations used to extract the AVO attributes applied in the present work. The most common AVO attributes used in the current industry practice are intercept and gradient. The intercept is the normal incidence compresional wave coefficient and gradient is slope. Shuey's equation (1985) can be expressed in term of intercept $(A)$ and gradient $(B)$ as. 
Table 1 Seismic parameters used for synthetic AVO modeling

\begin{tabular}{llll}
\hline & $V_{P}(\mathrm{~m} / \mathrm{s})$ & $V s(\mathrm{~m} / \mathrm{s})$ & $\rho_{\text {eff }}\left(\mathrm{gm} / \mathrm{cm}^{3}\right)$ \\
\hline Upper shale & 3,805 & 2,108 & 2.43 \\
Background sand & 3,600 & 1,897 & 2.34 \\
Gas saturated & 3,470 & 1,992 & 2.12 \\
Oil saturated & 3,485 & 1,936 & 2.24 \\
Bottom shale & 3,932 & 2,210 & 2.45 \\
\hline
\end{tabular}

$$
R_{P P}(\theta) \approx A+B \sin ^{2} \theta
$$

whereas,

$$
A=R_{P}=\frac{1}{2}\left(\frac{\Delta V_{P}}{V_{P_{\text {ave }}}}+\frac{\Delta \rho_{\text {eff }}}{\rho_{\text {eff }}}\right)
$$

Equation (9) represents the reflection coefficient at zero angle/offset $\left(A\right.$ or $\left.R_{P}\right)$ and slope is

$$
B=-2 \frac{V_{S_{\text {ave }}}^{2}}{V_{P_{\text {ave }}}^{2}} \frac{\Delta \rho_{\text {eff }}}{\rho_{\text {eff }}}+\frac{1}{2} \frac{\Delta V_{P}}{V_{P \text { ave }}}-4 \frac{V_{S_{\text {ave }}}^{2}}{V_{P_{\text {ave }}}^{2}} \frac{\Delta V_{S}}{V_{\text {Save }}}
$$

Here $\Delta V_{P}, \Delta V_{S}$, and $\Delta \rho_{\text {eff }}$ are the change in $\mathrm{P}$-wave velocity, $\mathrm{S}$-wave velocity and density across the interface and $V_{P \_a v e}, V_{S \_a v e}$ and $\rho_{e f f \_a v e}$ are the average P-wave velocity, S-wave velocity, and density of both mediums respectively.

AVO anomaly can be interpreted by crossploting intercept versus gradient. The reliability of this method depends on the accurate prediction of background trend. Successful hydrocarbon indicators show significant departure from background (Smith and Gidlow 1987) in the A-B plane. By calculating intercept and gradient from the above Eqs. (9) and (10), all other attributes like AVO product $(A \times B),(A+B) / 2$ etc. can be computed easily and can be crossplotted.

The $\mathrm{S}$ wave reflection coefficient $\left(R_{S}\right)$ for normal incident waves derived directly from the equation given as

$$
R_{S}=\frac{1}{2}\left(\frac{\Delta V_{S}}{V_{S_{\text {ave }}}}+\frac{\Delta \rho}{\rho_{\text {eff }}}\right)
$$

Verm and Hilterman (1995) gave the relation to compute the Poisson reflectivity $(P R)$, which depends on Poisson's ratio across the interface and can be computed by inverting the seismic velocities into Poisson's ratio.

$$
P R=\frac{\sigma_{2}-\sigma_{1}}{\left[1-\left(\sigma_{1}+\sigma_{2}\right) / 2\right]^{2}}
$$

$\sigma_{1}$ and $\sigma_{2}$ are the Poisson's ratio of upper and lower interface. Smith and Gidlow (1987) introduce the concept of fluid factor $(\Delta F)$ to highlight the gas bearing sandstone. $\Delta F$ is the difference between actual $\mathrm{P}$ wave reflection coefficient $R_{P}$ and calculated $R_{P}$ (from $\mathrm{S}$ wave reflection coefficient $R_{S}$ ) for the same sandstone in water saturated sandstone. Fluid factor is computed using equation give as 
Table 2 Reservoir parameters used in Gassmann fluid substitution modeling (modified from Khalid et al. 2014b)

\begin{tabular}{ll}
\hline & L-30 Well \\
\hline Reservoir interval & $2,638-2,662 \mathrm{~m}$ \\
Average reservoir temperature $(\mathrm{K})$ & 389.55 \\
Average effective pressure (MPa) & 26.234 \\
Fluid parameters & \\
Specific gravity of gas & 0.60 \\
Insitu gas density $\left(\mathrm{g} / \mathrm{cm}^{3}\right)$ & 0.143 \\
Bulk modulus of gas $(\mathrm{GPa})$ & 0.06 \\
Oil API & 47.60 \\
Insitu oil density (g/cm $\left.{ }^{3}\right)$ & 0.739 \\
Gas to oil ratio (Litre/litre) & 191.7 \\
Bulk modulus of oil $(\mathrm{GPa})$ & 0.939 \\
Insitu density of brine $\left(\mathrm{g} / \mathrm{cm}{ }^{3}\right)$ & 1.178 \\
Bulk modulus of brine $(\mathrm{GPa})$ & 3.12 \\
Rock parameters & \\
Bulk modulus of Quartz $(\mathrm{GPa})$ & 37 \\
Bulk modulus of Clay $(\mathrm{GPa})$ & 21 \\
Density of Quartz $\left(\mathrm{g} / \mathrm{cm}^{3}\right)$ & 2.65 \\
Density of Clay $\left(\mathrm{g} / \mathrm{cm}^{3}\right)$ & 2.58 \\
\hline
\end{tabular}

$$
\Delta F=R_{P}-1.16\left(\frac{V_{S}}{V_{P}}\right) R_{S}
$$

In our study area the reservoir (pay sand 4) porosity varies from 15 to $25 \%$. Corresponding to these porosities, we have selected twenty different samples from pay sand 4 intervals and by applying Gassmann fluid replacement modeling twenty different values of $K_{\text {sat }}$ are calculated for each fluid (oil, gas and brine). The values of $K_{\text {sat }}, \rho_{\text {eff }}$ and $\mu$ are substituted into Eqs. (5) and (6), to find out $V_{P}$ and $V_{S}$ for each pore fluids (oil, gas and brine). Seismic velocities of upper and lower shales are computed using sonic and density logs. By substituting these parameters into Eqs. (9)-(13) twenty values of each attributes $\left(A, B, P R, R_{S}, \Delta F\right)$ at upper (shale/pay sand 4) and lower (pay sand 4) interfaces have been calculated and crossplotted the appropriate pairs of these AVO attributes to find the best indicator to discriminate the fluids and lithologies. The rock physics parameters used in fluid substitution modeling are given in the Table 2 .

\section{Results}

The above described methodology is applied on real data set taken from the Scotian basin and the results are presented in many sections described below:

3.1 Seismic interpretation and petrophysical evaluation

Based on seismic and wireline logs interpretation the Mississauga Formation of early Cretaceous age is divided into three parts: upper, middle and lower Mississauga (abbreviated as 
UM, MM and LM respectively). The middle part of Mississauga Formation consists of five sands interbedded with shales. Sand 1 and 3 are below seismic resolution and hence cannot be picked on seismic data. The pay sand 4 (thickness $\sim 24 \mathrm{~m}$ ) contains the hydrocarbons in the study area and is mapped throughout the area. After picking it on seismic (Fig. 2a), the time structure map of pay sand 4 has been prepared (Fig. 2b). The interpretation of 3D seismic data and time contour map show that the study area consists of two low relief faulted anticlines (Fig. 2a, b). One anticline trending east-northeast direction and the other is southern anticline more has more eastern trend (Fig. 2b). Wade and Maclean (1990) interpreted about $12-14 \mathrm{~km}$ of Triassic/Early Jurassic to Tertiary sedimentary rocks overlying block faulted lower Paleozoic meta-sedimentary and igneous basement. To test the hydrocarbon potential in the prospect area; two wells (L-30 and B-41) were drilled on the basis of structural interpretation. The sand channels of Mississauga Formation were the targets in both wells. The repeat formation tests (RFTs) and petrophysical studies indicate the occurrence of light oil, gas and condensate in L-30 and no indication of hydrocarbons were found in B-41 well, therefore no RFTs were run. A well-defined petroleum system along with fluid migration path exists in the area under study.

Petrophysical analysis shows that the reservoir rock mainly consists on sandstone embedded with alternating layers of shale and the in situ reservoir pore fluids are oil, gas and brine. In the first part by crossplotting the GR and SP logs we have modeled the sand and shale facies of Mississauga Formation. The upper, middle and lower parts of Mississauga formation and five sand facies with interbedded shale in the middle part can be best visualized in Fig. 3a. The Mississauga sands have low GR values $(<60$ API), therefore show sharp decrease in GR values and also SP log shows more negative deflection for sandstone (permeable zone), which differentiating it from non-permeable shales.

A set of wireline logs i.e. gamma ray (GR), caliper, sonic, density, resistivity, spontaneous potential (SP) logs and neutron porosity are used for petrophysical study. The petrophysical study at shale imbedded pay sand 4 intervals $(2,438-2,462 \mathrm{~m})$ and results describe that it is mainly composed of sand with average porosity $(\phi)$ is $22 \%$ and permeability $(k)$ is 700 milli-darcy. Another important petrophysical parameter is volume of clay $\left(V_{c l}\right)$, required for rock physics modeling and also define the quality of reservoir as well. Volume of clay is calculated to estimate shale contents in the reservoir rock and GR log is used to estimate $V_{c l}$. On the basis of resistivity log and water saturation curve, the hydrocarbon containing zone has thickness about $4.3 \mathrm{~m}$ at 2,438 $\mathrm{m}$ depth is marked (Fig. 3b). In the net pay zone the resistivity values are very high and water saturation also a drop (34\%), which indicates the hydrocarbon bearing zone because salty water has low resistance to the current flow.

From the petrophysical study and facies modeling it is clear that the pay sand 4 contains hydrocarbon fluids and is also interbedded with upper and lower shale, which can be more clearly visualized in small seismic window as represented in Fig. 3c. Pay sand 4 has been shown on seismic by using GR and acoustic impedance (AI) logs (Fig. 3c). Sand facies has also low impedance and $A P I$ as compared to upper and lower shale.

\subsection{Pore fluids effect on AVO response}

The distribution of seismic velocities and densities of different pore fluids are the basic input required for AVO modeling and attribute analysis studies. The hydrocarbon fluids (especially free gas) present in reservoir influences the seismic wave propagations and results strong variation in seismic parameters (Fig. 4a). The $\mathrm{P}$ and $\mathrm{S}$ wave velocities, Poisson's ratio $(\sigma)$ and effective density as function of fluid saturation are plotted in Fig. 4a. These parameters are strongly depending on pore fluid type and saturation. As the water saturation $\left(S_{w}\right)$ decreases 
a $\mathrm{L}-30$

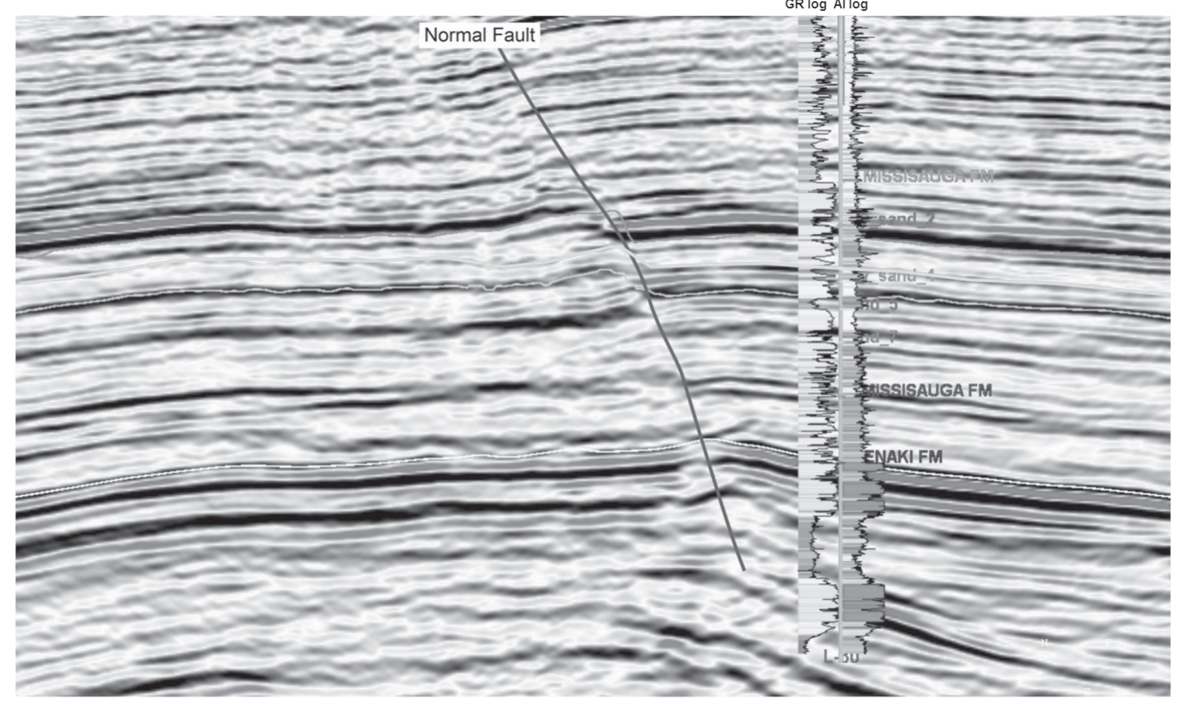

b

$\stackrel{N}{N}$

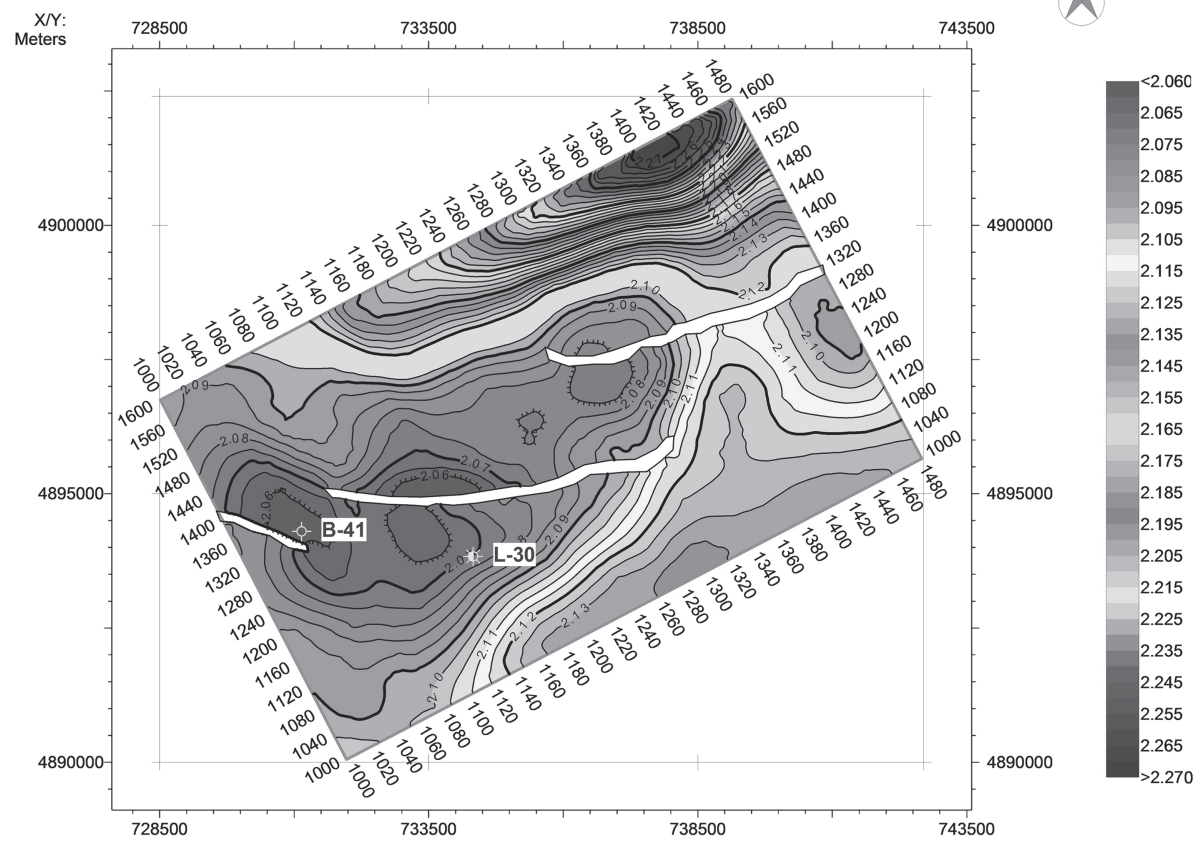

Fig. 2 a Interpreted crossline 1157 through the L-30 well showing a low relief faulted anticline. b Time structure map of pay sand 4 shows the north eastern anticline trends east northeast direction while the southern anticline trends towards east

(on the other hand gas saturation increases), the $V_{P}, \sigma$ and $\rho_{\text {eff }}$ decreases. However, $V_{S}$ increases with the increase in gas saturation. It is because the $S$ wave velocity depends on shear modulus and effective density. Shear modulus is independent on pore fluid type and saturation as result it remains constant but $\rho_{\text {eff }}$ decreases with gas which leads to an increase 

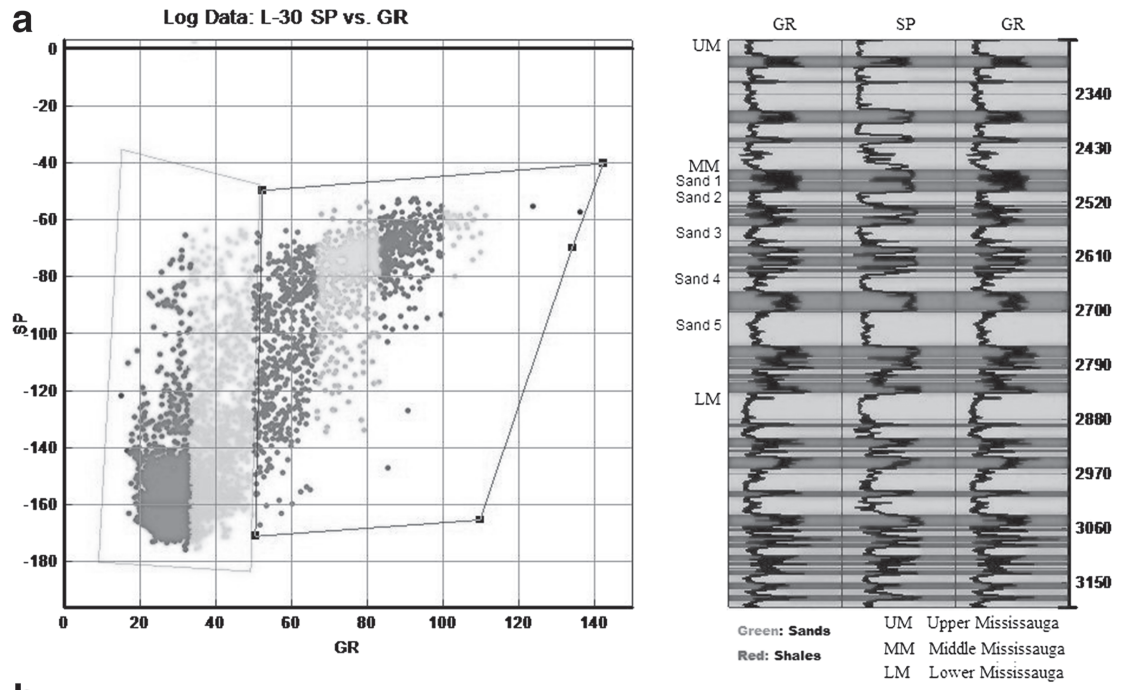

b
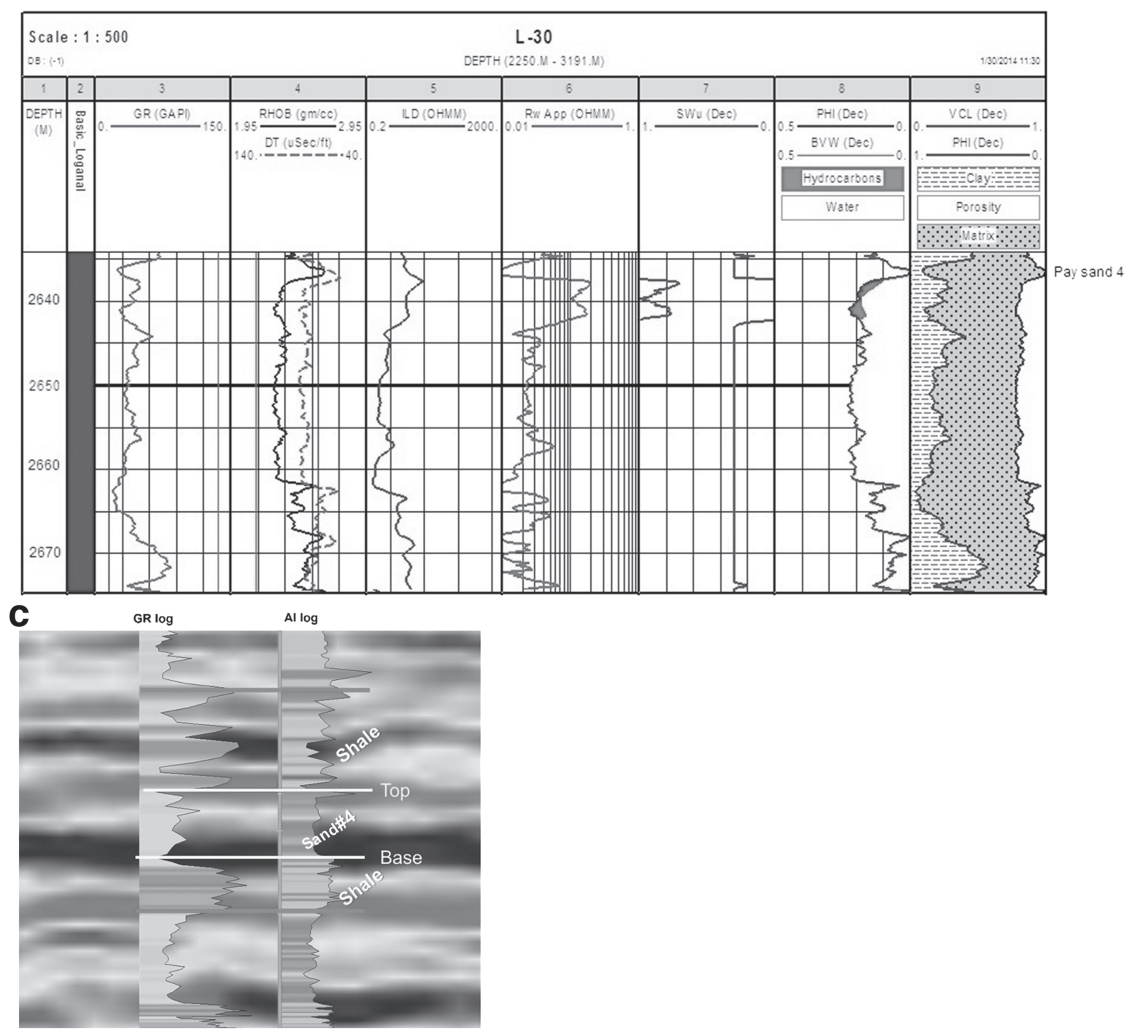

Fig. 3 a Facies modeling of the Mississauga sands in Penobscot well L-30. Gamma ray and SP logs are crossplotted to differentiate the sand and shale facies of reservoir rock. b Petrophysical study of pay sand 4 intervals to calculate the net pay zone c Very close look to shale/pay sands 4 and pay sand 4/shale on seismic with the help of GR and AI logs 


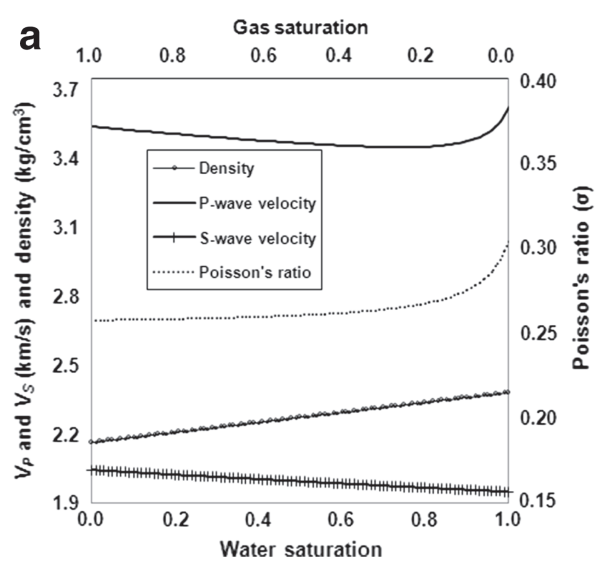

b

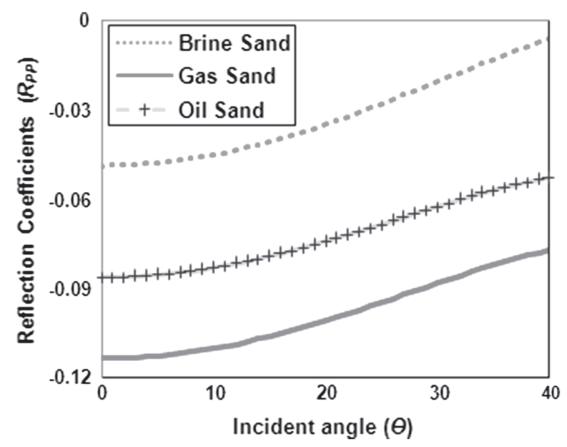

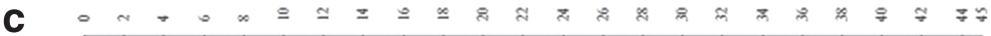

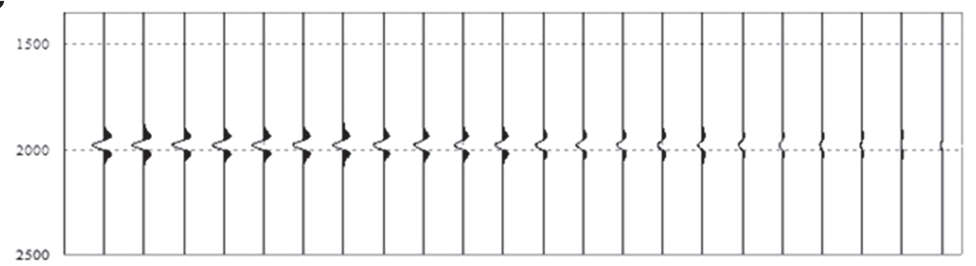

Brine Sand
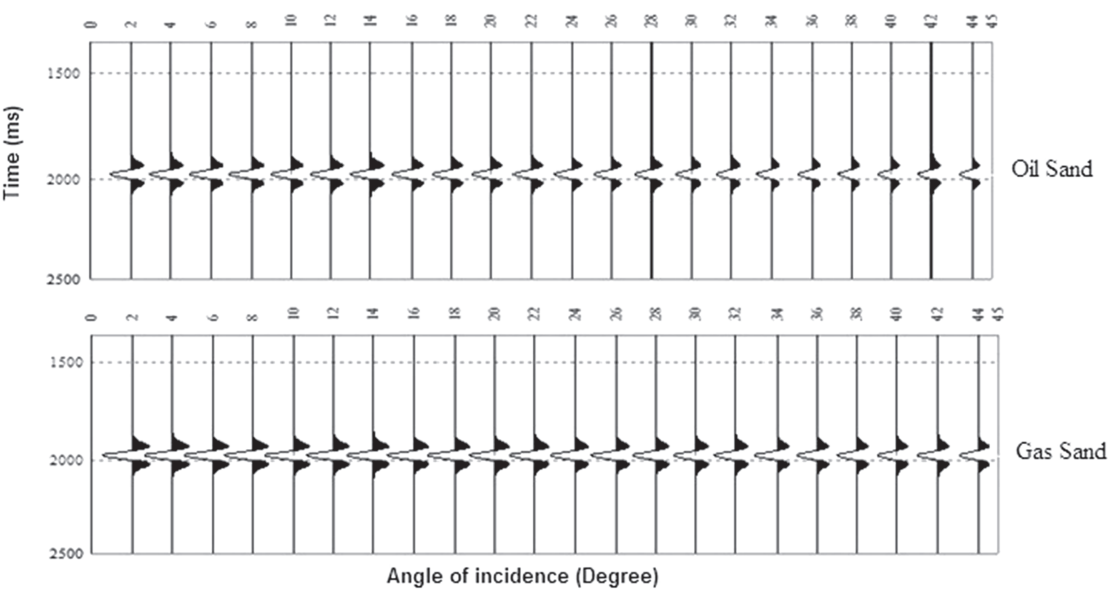

Fig. 4 a Pore fluid type and saturation effect on seismic properties of reservoir rock computed by using Gassmann's equation. b Amplitude versus angle (AVA) response at pay sand 4 interfaces when it is saturated with oil, gas and brine. $\mathbf{c}$ Synthetic CDP traces showing sensitivity of P-wave reflection amplitudes at the top of reservoir for brine, oil and gas

in $V_{S}$. The reflection amplitudes as a function of incident angles for oil, gas and brine saturated sands calculated using Zoeppritz equation are plotted up to incident angle 40 degree as shown in the Fig. 4b. From the Table 1 it is clear as brine replaces with oil and gas in the reservoir zone, the P-wave velocity and effective density drop while $\mathrm{S}$-wave velocity increases, which results the change in AVO response for oil, gas and brine saturated sands. For gas saturated sand the reflection amplitudes $\left(R_{P P}\right)$ as a function of incidence angles are higher as compared to oil and brine saturated sands (Fig. 4b), however in case of oil it is higher as with brine 
saturated sand. The reflection coefficient at normal angle of incident is higher and it decreases as incident angle increases. The gradient is similar in case of brine and gas sand, however it is lower in case of oil as presented in Fig. $4 \mathrm{~b}$.

Pore fluid effect on AVO is more clearly characterized by generating synthetic CDP gathers. Synthetic AVO models for brine, oil and gas sands are presented in Fig. 4c. These angles based seismograms show the more clear amplitudes sensitivity to pore fluid type and saturations (Fig. 4c). The reflection amplitudes at lower angles are higher and decreases as incident angle increases. The amplitude response in case of gas is similar to class IV gas sand reservoirs as discussed by Castagna et al. (1998).

\subsection{Interpretation of AVO crossplots}

In the present section we have displayed the results of AVO attributes and discussed how these attributes help to discriminate sand facies containing hydrocarbon fluids (oil, gas) from background geology (brine saturated sands). Our approach is to crossplot the suitable pairs of AVO attributes so that background lithologies and sand facies containing hydrocarbon fluids commanly bunch together and allow for simple and straightforward interpretation. The offtrend aggregations of sand facies from the fluid line are evaluated as possible hydrocarbon indicators. This is the spirit of successful AVO crossplot analysis and interpretation, all of which is based on the argument that data are anomalous statistically and is interesting geologically.

In the Fig. 5a intercepts and gradients calculated for twenty samples at the top and bottom interfaces are crossplotted in A-B plane. The top interface of all oil, gas and brine saturated sand facies has negative intercept and positive gradient, thus lie in quadrant II. This represents that the gas anomaly present in that area is classified as class IV reservoir. Figure 5a also represents the values of intercept for gas and oil is higher as compared to brine sand and more robustly discriminate the hydrocarbon fluids and also from background sands. On the other hand, there is great deal of overlap between oil, gas and brine sands in the direction of gradients. However, intercept versus gradient crossplot against each others, shows the clear deviation of hydrocarbon containing sands from the background trend (Fig. 5a). The intercept and gradient response computed at lower interfaces lies in the third quadrant. In Fig. 5b, the intercept-Poisson reflectivity pair is crossplotted for visual analysis of the classifying of the
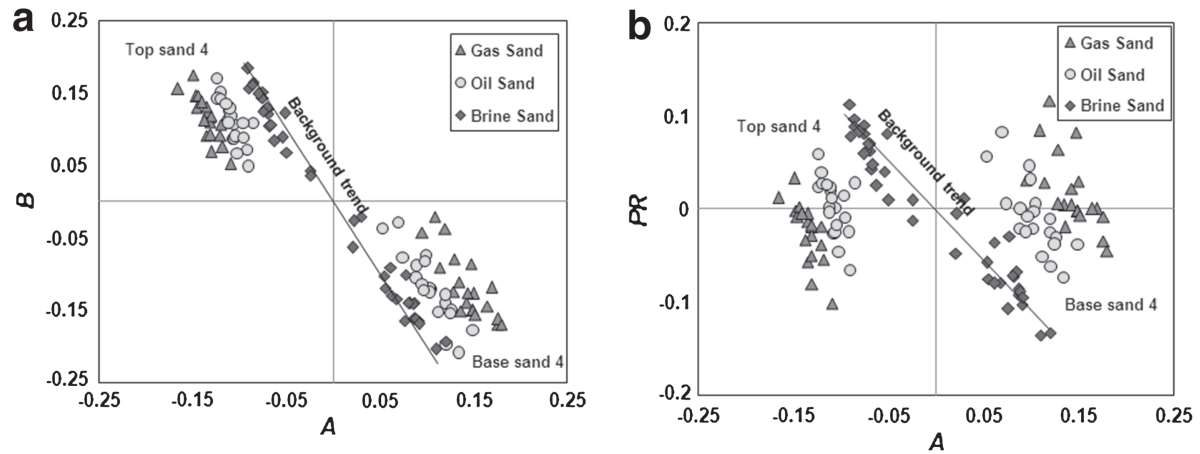

Fig. 5 a Intercept versus gradient crossplot for the modeled values of brine, gas and oil sand computed by fluid substitution at the top and base of pay sand 4 intervals. The hydrocarbon facies show clear deviation from background. b Crossplot of intercept versus Poisson reflectivity developed at upper and lower interface of reservoir for pore fluids (oil, gas and brine) 
Fig. 6 Normal incident $\mathrm{P}$ and $\mathrm{S}$ wave reflection coefficients $\left(R_{P}\right.$ and $R_{S}$ ) are plotted. The P-wave reflection coefficient is more sensitive as compare to S-wave but their combination also works well
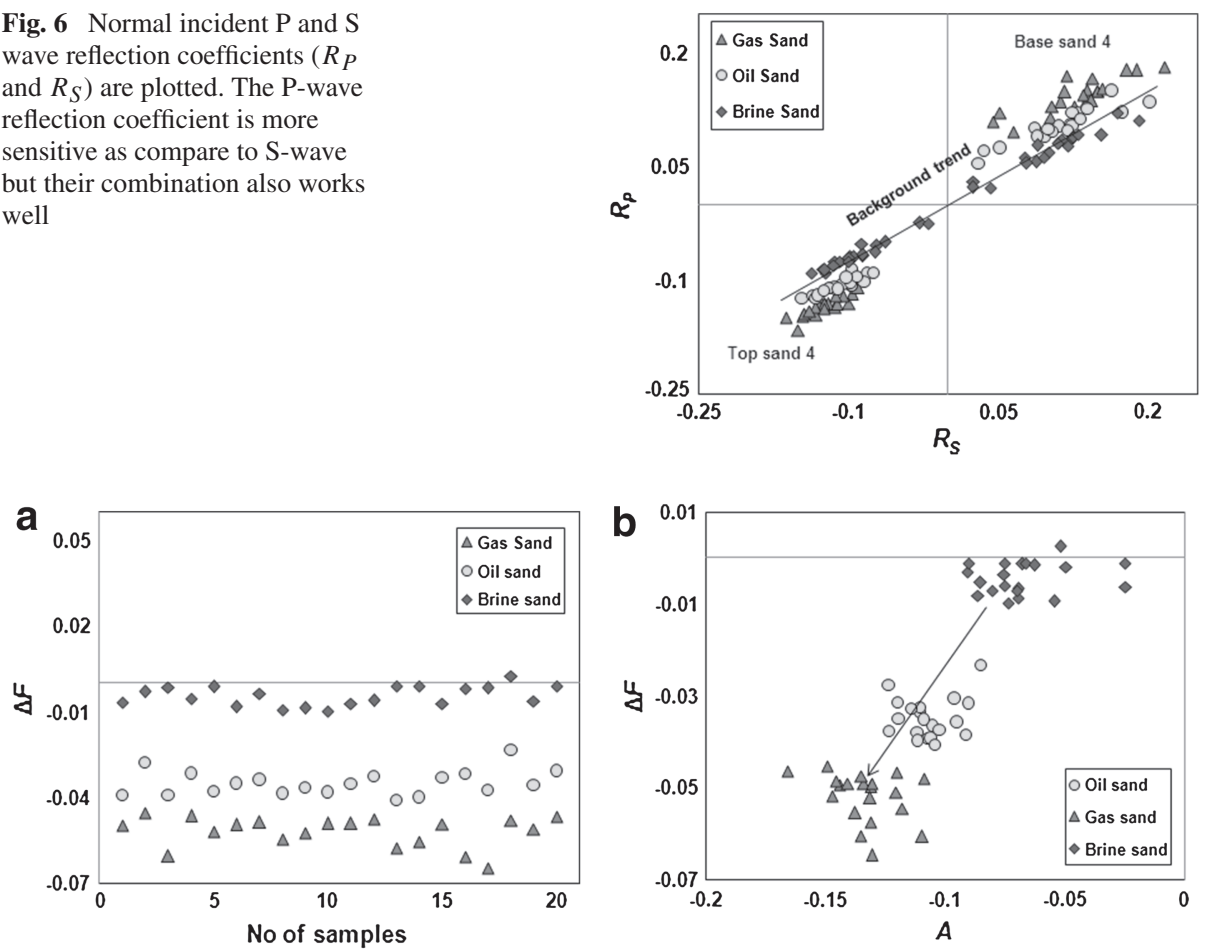

Fig. 7 a Fluid factor for twenty samples of hydrocarbon and wet sands at the upper interface is plotted. It is noted that fluid factor becomes near about zero for water bearing sands while high negative for gas bearing zones. b Fluid factor is plotted against intercept at the top of reservoir. A very clear deviation from wet sand can be visualized in the direction of $\Delta F$

lithologic boundaries like shale over brine saturated sands or a shale over hydrocarbon fluids (oil, gas) saturated sand facies. Since in most of the cases Poisson's ratio decreases (Fig. 4a) as water replaces with gas in the reservoir, that's why $P R$ acts very intuitive hydrocarbon indicator. More clear discrimination along the $P R$ axis can be visualized in Fig. 5b. At the upper (shale/sand) interface, the $P R$ has negative values for most gas sand samples and positive for brine sands and vice versa. In the Fig. 6 the $R_{P}$ and $R_{S}$ are plotted against each other. Inspection of the Fig. 6 reveals that the dependence of $R_{P}$ on pore fluid type is large as compared to $R_{S}$. In the $R_{P}$ versus $R s$ crossplot, $R_{P}$ is plotted along the y-axis and $R_{S}$ along x-axis. $R_{P}$ and $R_{S}$ both have negative values for brine and hydrocarbon saturated sands, hence the top of reservoir lies in the quadrant III and vice versa. There is strong overlapping between the brine, gas and oil saturated sand facies at the upper and lower interface exists in the direction of $R_{S}$ shows it is less sensitive to pore fluid types. However when it is crossplotted against $R_{P}$, the combination of these both attributes work well.

Fluid factor $(\Delta F)$ is an excellent indicators used to identify the gas bearing sand facies. The $\Delta F \sim 0$ if the reflection lies at mudrock line and $\Delta F \neq 0$ if reflection lies the offtrend from mudrock line. For example fluid factor is expected to be zero for water bearing sands and non-zero at the top of hydrocarbon (oil/gas) bearing zones. In the Fig. 7a $\Delta F$ is plotted for twenty samples oil, gas and brine saturated pay sand 4 facies. It can be observed that the fluid factor equals to be near about zero when it comes to water bearing pay sand 4 and it will be non-zero when it comes to be hydrocarbon bearing zones. In the Fig. $7 \mathrm{~b}$ 
the fluid factor is crossplotted along with intercept. Very clear discrimination between the hydrocarbon containing pay sand 4 facies and water bearing sandstone can be viewed. The deviation in case of gas sands is always higher as compared to oil, so fluid factor is more intuitive and robust AVO attribute as compared to all other attributes.

\section{Conclusions}

AVO based attributes are excellent indicators for identifying the hydrocarbon containing sand facies from background sands. Although a large number of attributes are in practice and a number of them are upcoming with an improved accuracy and understanding of reservoir facies and fluid discrimination, but their effectiveness primarily depends on the signal to noise ratios of pre-stack seismic data. Various combinations of AVO derived attributes have been studied as hydrocarbon indicators to discriminate hydrocarbon sand facies from nonhydrocarbon sand facies in Mississauga Formation of early Cretaceous of Nova Scotia area. Our analysis reveals that AVO forward modeling and attributes analysis are helpful techniques to model the AVO response. Amplitude versus angles curves and intercept-gradient analysis demonstrates that gas anomaly in the study area is classified in class IV sand reservoir. However, the $\Delta F$ and $A$ are more sensitive to the pore fluid type and saturation as compared to $B$ and $R_{S}$. The more intuitive indicators need to be calibrated and tested for local settings.

Acknowledgments The authors would like to acknowledge to dGB Earth Sciences for providing data. We are grateful to Farrukh Qayyum (dGB Earth Sciences, The Netherlands) for valuable discussions. We owe a lot of it to K-tron GeoStudio for providing the licenses of their software for the completion of this work. Seismic Micro Technology (SMT) provides the Kingdom 8.4 to the Institute of Geology is also acknowledged.

\section{References}

Ahmed N (2013) Rock physics modeling and sensitivity analysis of AVO derived indicators to discriminate fluids and lithologies of Penobscot area, Nova scotia, Canada. Dissertation, University of the Punjab.

Aki K, Richards PG (1980) Quantitative seismology: theory and methods. W. H. Freeman, San Francisco

Batzle ML, Han DH, Hofmann R (2001) Optimal hydrocarbon indicators. In: Annual International Meeting, SEG expanded abstracts. San Antonio, Texas, pp 1697-1700

Berryman JG, Berge PA, Bonner BP (2002) Estimating rock porosity and fluid saturation using only seismic velocities. Geophysics 67:39-404

Biot MA (1941) General theory of three-dimensional consolidation. J Appl Phys 12:155-164

Bortfeld R (1961) Approximation to the reflection and transmission coe? Coefficients of plane longitudinal and transverse waves. Geophys Prospect 9:485-502

Castagna JP, Batzle ML, Eastwood RL (1985) Relationships between compressional and shear-wave velocities in clastic silicate rocks. Geophysics 50:551-570

Castagna JP, Smith SW (1994) Comparison of AVO indicators: a modeling study. Geophysics 59:1849-1855

Castagna JP, Swan HW (1997) Principles of AVO crossplotting. Lead Edge 16:337-342

Castagna JP, Swan HS, Foster DJ (1998) Framework for the interpretation of AVO intercept and gradient. Geophysics 63:948-956

Chen T, Goodway B, Zhang W, Potocki D, Calow B, Gray D (1998) Integrating geophysics, geology and petrophysics: a 3D seismic AVO and borehole/logging case study. In: 68th Annual international meeting of SEG expanded abstracts, paper INT 2.6

Chopra S, Alexeev V, Xu Y (2003) 3D AVO Crossplotting — an effective visualization technique. SEG technical program expanded abstracts, pp 189-192

Connolly P (1999) Elastic impedance. Lead Edge 18:438-452

Fatti JL, Vail PJ, Smith GC, Strauss PJ, Levitt PR (1994) Detection of gas in sandstone reservoirs using AVO analysis: a 3-D seismic case history using the geostack technique. Geophysics 59:1362-1376 
Foster DJ, Keys RG, Schmitt DP (1997) Detecting subsurface hydrocarbons with elastic wavefields. In: Chavent G, Papanicolaou G, Sacks P, Symes W (eds) Inverse problems in wave propagation. Springer Verlag, Berlin

Gassmann F (1951) Uber die Elastizitat poroser Medien. Vierteljahrsschr Natforsch Ges Zür 96:1-23

Goodway W, Chen T, Downton J (1997) Improved AVO fluid detection and lithology discrimination using Lamé petrophysical Parameters; "Lambda-Rho", "Mu-Rho", and "Lambda/Mu fluid stack", from P and S inversions. In: 67th Annual international meeting, SEG expanded abstracts, pp 183-186

Gray D, Goodway W, Chen T (1999) Bridging the gap: using AVO to detect changes in fundamental elastic constants. In: Annual international meeting, SEG expanded abstracts, pp 852-855

Greenberg ML, Castagna JP (1992) Shear-wave velocity estimation in porous rocks: theoretical formulation, preliminary verifications and applications. Geophys Prospect 40:195-209

Hedlin K (2000) Pore space modulus and extraction using AVO. In: 70th Annual international meeting, SEG expanded abstracts, pp 170-173

Hill R (1952) The elastic behavior of a crystalline aggregate. Proc Phys Soc Lond Ser A 65:349-354

Hilterman F (2001) Seismic amplitude interpretation. SEG distinguished instructor short course

Jing-Ye L (2012) Gas reservoir identification by seismic AVO attributes on fluid substitution. Appl Geophys 9:139-148

Khalid P, Ghazi S (2013) Discrimination of fizz water and gas reservoir by AVO analysis: a modified approach. Acta Geod Geophys 48:347-361

Khalid P, Brosta D, Nichita DV, Blanco J (2014a) A modified rock physics model for analysis of seismic signatures of low gas-saturated rocks. Arab J Geosci 7:3281-3295

Khalid P, Ahmed N, Khan KA, Naeem M (2014b) AVO-derived attributes to differentiate reservoir facies from non-reservoirs facies and fluid discrimination in Penobscot area, Nova Scotia. Geosci J. doi:10.1007/ s12303-014-0048-0

Khan KA, Akhter G, Ahmad Z (2010) OIL_output input language for data connectivity between geoscientific software applications. Comput Geosci 36:687-697. doi:10.1016/j.cageo.2009.09.005

Krief M, Garat J, Stellingwerff J, Ventre J (1990) A petrophysical interpretation using the velocities of P and S waves (full-waveform sonic). Log Anal 31:355-369

Mavko G, Mukerji T, Dvorkin J (2009) The rock physics handbook. Cambridge University Press, Cambridge

Murphy W, Reischer A, Hsu K (1993) Modulus decomposition of compressional and shear velocities in sand bodies. Geophysics 58:227-239

Quakenbush M, Shang B, Tuttle C (2006) Poisson impedance. Lead Edge 25:128-138

Reuss A (1929) Berechnung der fliessgrense von mischkristallen auf grund der plastizitatbedingung fur einkristalle. Zeitschrift furAnge-wandte Mathematik aus Mechnik 9:49-58

Ross CP, Kinman DL (1995) Non-bright spot AVO: two examples. Geophysics 60:1398-1408

Ross CP (2000) Effective AVO crossplot modeling: a tutorial. Geophysics 65:700-711

Russell B, Hedlin K, Hilterman F, Lines L (2003) Fluid-property discrimination with AVO: a Biot-Gassmann perspective. Geophysics 68:29-39

Shuey RT (1985) A simplification of the Zoeppritz equations. Geophysics 50:609-614

Smith GC, Gidlow PM (1987) Weighted stacking for rock property estimation and detection of gas. Geophys Prospect 35:993-1014

Swan HW (1993) Properties of direct AVO hydrocarbon indicators. In: Castagna JP, Backus MM (eds) Offsetdependent reflectivity - theory and practice of AVO analysis. Soc Expl Geophys, pp 78-92

Thaper MR (2012) AVO and attributes for reservoir analysis. In: Extended abstract. International geophysical conference and oil \& gas exhibition, Istanbul, Turkey, 7-19 September 2012.

Verm R, Hilterman FJ (1995) Lithology color-coded seismic sections: the calibration of AVO crossplotting to rock properties. Lead Edge 14:847-853

Voigt W (1910) Lehrbuch der Kristallphysik. Teubner, Leipzig

Wade JA, Maclean BC (1990) The geology of the southeastern margin of Canada. In: Keenand MJ, Williams GL (eds) Geology of North America. Geological Society of America, Boulder, pp 167-238

Wood AB (1941) A textbook of sound. G. Bell and sons, London

Zoeppritz K (1919) Erdbebenwellen VIIIB, On the reflection and propagation of seismic waves. Göttinger Nachrichten I:66-84 